\title{
Primary School Children Cognitive Processes Development Research
}

\author{
Kabylova Almakhan, Kussainova Manshuk \\ Department of Pedagogy, Institute of Advanced Training for Teachers, Aktau City, Kazakhstan \\ Email: manshuk61@mail.ru
}

Received 23 December 2013; revised 23 January 2014; accepted 30 January 2014

Copyright (C) 2014 by authors and Scientific Research Publishing Inc.

This work is licensed under the Creative Commons Attribution International License (CC BY). http://creativecommons.org/licenses/by/4.0/

(c) (i) Open Access

\begin{abstract}
One of the important directions of school psychologist work with children is cognitive area development. Development problem, correction and improvement of learners' intellect abilities are one of the most important in psychological-pedagogic practice. It is fairly considered that its main way of solution is rational organization of all the educational process. Specially organized game training of thinking can be considered as a supplementary. The paper presents a research of primary school children including different methods such as E. Lan dolt rings, Raven matrix, Rubiks cube. Children from the $1^{\text {st }}$ to the $4^{\text {th }}$ grade at the age of 7 to 11 , total number 80, participated in the research. The research was conducted on the basis of school No. 6 (Aktau city, Kazakhstan). The conclusion was made that those children with low results have weakly developed image-efficient thinking. Children with average results have demonstrated visual-efficient thinking as average developed. And children with high results have demonstrated high developed visual-efficient thinking. Important psychic functions for primary school children are perception, memory and imagination, but of course the most important at this age is thinking development. None of the psychic functions can be developed without thinking.
\end{abstract}

\section{Keywords}

Cognitive Process; Primary School Children Development; Visual-Efficient Thinking; Image-Efficient thinking; Psychic Functions

\section{Introduction}

Teachers' multiple observations have shown that a child who has not learnt how to study and acquire ways of intellectual activity in primary school usually becomes underachiever at secondary school. One of the solutions is creating conditions in primary school providing children's complete mental development connected with the formation of stable cognitive interests, skills and abilities of thinking activity, intellect qualities and creative initiative. 
Development problem, correction and improvement of learners' intellect abilities are one of the most important problems in psychological-pedagogic practice.

It is fairly considered that its main way of solution is rational organization of all the educational process. Specially organized game training of thinking can be considered as a supplementary.

\section{Results of Psychodiagnostic Research}

There are reasons to consider that the general base for full value of any intellectual process is the availability of three minimum universal components of mental abilities:

1) High level of formation of elementary intellectual operations: analysis, synthesis, comparison, singling out the most significant and others, acting as the most fractional elements of thinking;

2) High level of activity, unselfconsciousness and pluralisticity of thinking reveals in producing a great number of different hypotheses;

3) High level of organization and purposefulness of thinking, being revealed in distinct orientation for singling out the most significant in the phenomena, using general schemes of phenomenon analysis.

Obviously all psychic functions are very important: memory, attention, imagination, but still the leading cognitive process is thinking. Thinking is one of the most important functions in the psychic. It is likely that without thinking there would be no any other higher mental functions.

In the present paper we would like to present the results of psychodiagnostic research of primary school children during their studies at school. However, we accentuated thinking development at this age.

In our opinion, diagnostic methods should meet the following requirements:

1) Used methods should adequately reveal the level of the development of cognitive processes at primary school age;

2) Reliability of character determination and cognitive processes development condition. Definite qualitative and quantitative factors and criteria should serve this. Development of unified conditions of the methods usage to compare received data has special significance.

3) It is necessary to conduct the research no longer than one hour, as children of primary school age are characteristic of instability of activity factors and also their deterioration while continuous completion of intellectual assignments.

One of the most important conditions, the basis and means of personality development is learning process. In this connection L. S. Vygotskiy formulated the statement, according to which teaching and up-bringing play the leading role in the psychic development of a child, as "teaching goes before development, moving it further and causing new growth in it” (Vygotskiy, 1982).

Methods used while primary school children diagnosis were selected taking into account peculiarities of this age. 10-point scale of assessment was used in all the methods presented below.

Attention is a psychic process, the characteristics of which is responsible for cognitive readiness of the child. Many problems arising while studying especially at the beginning stage of it are directly connected with the gaps in attention development.

Lan dolt rings were selected as the main methodical stimulating material to evaluate stability, distribution and attention switch of primary school children, because they are a universal means that can be used to study children's attention of different ages from primary to senior school age. It is presented in the following way. A standard piece of paper- “a form" where rings with openings in different part of the ring is drawn. To research attention productivity and stability the child is given a form with the following instruction: "Now we will play a game called "Be attentive and work as fast as you can". You are going to compete with other children in this game and then we will see what result you have achieved in the competition with them. I am sure you will do your best".

The work is conducted during 5 minutes. Every minute the examiner says: "line", at this moment the child has to draw a line in the form with Lan dolt rings when he heard the command.

After 5 minutes the examiner says: "Stop". After this command the child has to stop the work where he heard the command and draw a double vertical line. While processing the results the researcher determines the number of rings that have been looked through by the child for every minute and during all five minutes that psycho diagnostic experiment lasted. Also he determines the number of mistakes made during the work at every minute, from the first to the fifth and on the whole during all five minutes.

Attention productivity and stability of the child is determined according to the formula: 


$$
S=\frac{0.5 N-2.8 n}{60}
$$

where: S-is the index of attention productivity and stability;

$\mathrm{N}$-is the number of rings, looked through by the child during 1 minute;

$\mathrm{N}$-is the number of mistakes, made by the child.

During results processing five minute indexes $\mathrm{S}$ are calculated and one index $\mathrm{S}$, related to all five minutes of work, altogether.

The next component is attention distribution. Instruction that children receive in this method is nearly the same with that of Lan dolt rings. The same stimulus material is used in this test. However in this case children were offered to find and cross out two different at the same time rings, having the opening in different places, and also the first ring should be crossed out using one way and the second ring using another one.

Attention switch assessment. Here children are also offered a form with Lan dolt rings as in previous cases, but they are provided with another instruction:

"During the first minute you will have to find and cross using one way the rings of one type (with one orientation of opening), and during the next minute-rings of another type (with another orientation of opening) and then in turn during all five minutes”. Processing, presentation and interpretation of the results are the same as in previous methods.

We assessed child's attention capacity using 10-point scale. We have the data that average attention capacity of an adult is 3 - 7 units. For children of senior primary school age and junior school age its lower boundary is 3 units. Apparently, it is the same as for adults. As for upper boundary it definitely depends on the age, as attention and its capacity is certainly being developed in childhood.

Besides, human memory is more multidimensional than his attention. When a child enters school for his success in studying in primary school it is necessary to know at least the following kinds of memory: short-time visual memory, including capacity and ability to keep information in corresponding kinds of operative memory; mediated memory, which is characterized by the ability and independent initiative use by the child different means of information remembering, storage and reproduction. It is also important to assess dynamic peculiarities of remembering process correctly and exactly, including such indexes as dynamics of memorizing and its productivity, the number of repetitions necessary for error-free recall of a definite number of units and information. But at first it is necessary to consider the capacity of short-term visual memory.

The child is offered the pictures in turn, After showing every part of the picture, the child receives screen frame and is asked to draw all the lines he had seen and remembered on every part.

According to the results of two tests average number of lines is determined that he reproduced from memory correctly.

The line is considered reproduced correctly if the length and orientation is not different from the length and orientation of the corresponding line on the original picture (deviation from the beginning or end of the line for more than one square preserving its angle decline). Received index, equal to the number of correctly reproduced lines is considered as visual memory capacity.

Next component is mediated memory. Test materials are a piece of paper and a pen. Before the test the child is provided with the following instruction:

"I am going to name different words and sentences now and then make a pause. During this pause you will have to draw or write something that will allow you to remember and then recall those words that I pronounce. Try to draw and write as quickly as possible. Otherwise we will not be able to complete all the assignments”.

Next component is dynamic peculiarity of memorizing process.

The child is offered a row consisting of 10 simple words for remembering by their multiple repetition. After every regular repetition a number is determined of the row that the child managed to reproduce without mistakes after such repetition.

The number of repeated presentations of the row and subsequent attempts of their reproduction in this method is limited by six and with every attempt of reproduction the number of correctly reproduced words are correlated. The following two indexes of memorizing dynamics are determined: memorizing dynamics and memorizing productivity.

The next part of the research method is about primary school children memorizing productivity. This methods was conducted in the same way as the previous one but the number of the memorized words are examined after one hour.

Undoubtedly memory is an important structure of a human brain but it is impossible to imagine human 
memory existence without thinking. The human is capable of transmitting information from the external world to the inner world and remember it only owing to different thinking processes in the human's head. Besides imagination plays an important role in thinking processes development.

A child's imagination is evaluated according to the degree of his fantasy development, which in its turn can be revealed in stories, pictures, articles and other products of creative activity. In this connection the child is offered to complete the following assignment.

Make a story (fairy-tale) about some living being (a human, an animal) or something else according to the child's choice and tell it orally during 5 minutes. The child is given one minute to make the plot of the story and then he/she starts telling the story.

During the story the child's fantasy is evaluated according to the following characteristics:

- Imagination processes speed;

- Images originality and irregularity;

- Fantasy richness;

- Depth and elaboration (specialization) of the images.

But as it has been mentioned above none of the psychic functions is capable of developing at full value without thinking.

Primary school child thinking is different from preschool child thinking, firstly, by higher rates of his development during those years; secondly, by essential structural and qualitative transformations, taking place in the intellectual processes themselves. All three types of thinking are actively being developed as the leading activity at primary school age under the influence of education process: visual-efficient, visual-imaginative and verbal-logic.

Especially significant changes take place in the development of the latter type of thinking, which is relatively deficient in the beginning of this period of the child's life. And by the end of it, i.e. early teen age becomes the most important and is not different from that of adults. In this connection practical psycho diagnostic research of primary school children thinking should be directed at the evaluation of all types of thinking of the child, on the one hand, and special assessment of verbal-logic thinking, on the other hand. In this connection the following methods described below will be used.

The method represents a set of flat figures — squares, triangles and circles of three different colors (red, yellow, green — other combinations are possible) and three different sizes. These figures characteristics are: form, color and size form three letters artificial notions, having no meaning in the child's native language.

Cards with different colors figures are placed in front of the child so that the child could see and study them at the same time. The cards can be placed in three rows seven cards in every row, placing six of them in an incomplete row.

The next component is visual-image thinking. Method used for diagnoses of this type of thinking is called "Raven matrix". Here visual-image thinking is understood as the one connection with operating by different images and visual representations while solving the tasks.

Specific tasks used to test the level of the development of visual-image thinking in this research are taken from a well-known Raven test. They represent specially chosen selection of 10 gradually complicating Raven matrixes.

The child is offered a series of 10 gradually complicating tasks of a similar type: the search of regularities in matrix details position and the choice of one of the eight pictures as a missing insert to this matrix, corresponding to its picture.

Having studied the structure of the big matrix the child has to point out the part that fits the best to the picture or according to the logics of its parts position vertically or horizontally. Children are given 10 minutes to complete those assignments. Upon the expiry of this time the experiment is stopped and the number of correctly solved matrixes is determined.

The next method is called "Rubik's Cube". This method is meant to diagnose the level of visual-activity thinking development.

Using a well-known Rubik's Cube the child is given practical tasks of different level of complexity and is offered to solve them in the conditions of time deficit. One minute is given to solve one task (there are nine tasks totally).

All tests results were analyzed during the next stage.

Children from the $1^{\text {st }}$ to the $4^{\text {th }}$ grade at the age of 7 to 11 total number 80 participated in the research.

The research was conducted on the basis of school No. 6 (Aktau city, Kazakhstan). 


\section{Empiric Research Results Analysis}

Further research was based on the diagnostics results analysis with the aim of studying peculiarities of psychic cognitive processes development at primary school age. Table 1 represents matrixes of test results, diagnosing attention processes. Comparative Tables 1-4 were composed and are presented below.

Table 1. Indexes of attention productivity and stability at primary school age.

\begin{tabular}{rcccccc}
\hline & \multicolumn{7}{c}{ Attention productivity and stability } \\
\cline { 2 - 7 } Grades & \multicolumn{7}{c}{ High results } & Average results & Low results \\
\cline { 2 - 7 } & Number of learners & $\%$ & Number of learners & $\%$ & Number of learners & $\%$ \\
\hline $1^{\text {st }} \mathrm{N}=23$ & 6 & 26 & 17 & 84 & 0 & 0 \\
$2^{\text {nd }} \mathrm{N}=20$ & 7 & 35 & 13 & 65 & 0 & 0 \\
$3^{\text {rd }} \mathrm{N}=20$ & 17 & 85 & 3 & 15 & 0 & 0 \\
$4^{\text {th }} \mathrm{N}=16$ & 13 & 81 & 3 & 19 & 0 & 0 \\
\hline
\end{tabular}

Table 2. Indexes of attention distribution at primary school age.

\begin{tabular}{rcccccc}
\hline & \multicolumn{7}{c}{ Attention distribution } \\
\cline { 2 - 7 } Grades & \multicolumn{7}{c}{ High results } & Average results & Low results \\
\cline { 2 - 7 } & Number of learners & $\%$ & Number of learners & $\%$ & Number of learners & $\%$ \\
\hline $1^{\text {st }} \mathrm{N}=23$ & 3 & 13 & 20 & 87 & 0 & 0 \\
$2^{\text {nd }} \mathrm{N}=20$ & 7 & 35 & 13 & 65 & 0 & 0 \\
$3^{\text {rd }} \mathrm{N}=20$ & 18 & 90 & 2 & 10 & 0 & 0 \\
$4^{\text {th }} \mathrm{N}=16$ & 13 & 81 & 3 & 19 & 0 & 0 \\
\hline
\end{tabular}

Table 3. Indexes of attention switch at primary school age.

\begin{tabular}{rcccccc}
\hline & \multicolumn{7}{c}{ Attention distribution } \\
\cline { 2 - 7 } Grades & \multicolumn{7}{c}{ High results } & & Average results & Low results \\
\cline { 2 - 7 } & Number of learners & $\%$ & Number of learners & $\%$ & Number of learners & $\%$ \\
\hline $1^{\text {st }} \mathrm{N}=23$ & 0 & 0 & 4 & 17 & 19 & 83 \\
$2^{\text {nd }} \mathrm{N}=20$ & 0 & 0 & 6 & 30 & 14 & 70 \\
$3^{\text {rd }} \mathrm{N}=20$ & 17 & 85 & 3 & 15 & 0 & 0 \\
$4^{\text {th }} \mathrm{N}=16$ & 14 & 88 & 2 & 13 & 0 & 0 \\
\hline
\end{tabular}

Table 4. Indexes of attention capacity at primary school age.

\begin{tabular}{|c|c|c|c|c|c|c|}
\hline \multirow{3}{*}{ Grades } & \multicolumn{6}{|c|}{ Attention distribution } \\
\hline & \multicolumn{3}{|c|}{ High results } & \multicolumn{2}{|r|}{ Average results } & \multirow{2}{*}{$\begin{array}{c}\text { Low results } \\
\%\end{array}$} \\
\hline & Number of learners & $\%$ & Number of learners & $\%$ & Number of learners & \\
\hline $1^{\text {st }} \mathrm{N}=23$ & 0 & 0 & 3 & 13 & 20 & 87 \\
\hline $2^{\text {nd }} \mathrm{N}=20$ & 0 & 0 & 6 & 30 & 14 & 70 \\
\hline $3^{\text {rd }} N=20$ & 18 & 90 & 2 & 10 & 0 & 0 \\
\hline $4^{\text {th }} \mathrm{N}=16$ & 14 & 88 & 2 & 12 & 0 & 0 \\
\hline
\end{tabular}


According to the results of the research the following conclusion can be made: attention productivity and stability during schoolchildren education process was developing dynamically enough as first two grades have higher per cent of the average level $84 \%$ and $65 \%$ correspondingly, then in the $3^{\text {rd }}$ and $4^{\text {th }}$ grade $85 \%$ and $81 \%$ have high index. This is connected with the fact that psychic function is not developed enough with $7-9$ year old children and in this connection most children had average points, but at the age of 9 - 11 this function is nearly formed completely, so most of the children received the maximum number of points on this method.

Thus attention productivity and stability at primary school age is dynamically changing from average values to high ones. Meanwhile if in the $1^{\text {st }}$ and $2^{\text {nd }}$ grade average degree of intensity was registered 4,5 times oftener than in the $3^{\text {rd }}$ and $4^{\text {th }}$ grades, than high degree of attention productivity and stability intensity is $6-9$ times higher in comparison with average indexes of attention productivity and stability intensity at primary school age.

On the basis of data presented it is possible to make the conclusion that represented type of attention is more dynamically developed till the $3^{\text {rd }}$ grade, but in the $4^{\text {th }}$ grade there is a slight decrease of attention level. Thus in the $1^{\text {st }}$ grade $13 \%$ of school children have high results, in the $2^{\text {nd }}$ grade they are $35 \%$ and $90 \%$ in the $3^{\text {rd }}$, but in the $4^{\text {th }}$ grade the per cent of children having high results is only $81 \%$. As we can see annually the dynamics of increasing the ability for attention distribution increases 2.5 - 3 times. Data of attention measurement prove that as a result of education process influence children at primary school age learn to have several objects in view and can adequately behave in the situation with several stimuli at the same time.

Attention switch is worse than other types of attention. Here $1^{\text {st }}$ and $2^{\text {nd }}$ grade attention switch is not higher than average point.

Judging from this table we can make the conclusion that attention switch in two first grades is at a low level. As for $3^{\text {rd }}$ and $4^{\text {th }}$ grade the level of attention switch development is at a higher degree of development.

It is important to remember that it is primary school age when children first face the situation when during limited time they have to complete quickly and distinctly the teacher's instruction and switch their attention from one assignment to another and at the same time finish the assignment and adequately start the new one.

Such situation of attention switch indexes change is quite regular for children whose activity before school life was reduced to game only and the ability to switch attention under the guidance of an adult in the situation of limited time and without possibility of choice.

Next component is attention capacity. This method is used in the form that it was presented before.

The following conclusion can be made that attention capacity development in the $1^{\text {st }}$ and $2^{\text {nd }}$ grade has average and lower than average results. $90 \%$ of $3^{\text {rd }}$ grade children have high results, $10 \%$-average results. $88 \%$ per cent of children in the $4^{\text {th }}$ grade have high results and $12 \%$-average. In this connection the following conclusion can be made, that children attention capacity is increasing in the $3^{\text {rd }}$ and $4^{\text {th }}$ grades. Attention capacity is not developed enough at a younger age. Still attention development depends on the level of thinking development as the main psychic function is thinking and it can be traced especially distinctly at a primary school age.

Changes, observed according to attention capacity index are quite regular as during education activity primary school children are forced to remember enough education material that creates training situation and leads to this psychic function development.

On the basis of Table 5 per cent values were calculated, received on the basis of methods processing for the research of visual short-term memory capacity (Tables 5-8).

As it is seen from the table, high, average and low indexes of short-term visual memory capacity in every grade are expressed in different ways. Most children in the $1^{\text {st }}$ grade have low level however they have high rates of this psychic function in comparison with other, elder age groups they have the highest rate of $22 \%$, whereas in the second grade it is $20 \%$ and $3^{\text {rd }}$ and $4^{\text {th }}-10 \%$ and $19 \%$ correspondingly. There is an increase of medium degree of short-term visual memory intensity in the $2^{\text {nd }}$ grade. Short-term visual memory capacity in the $3^{\text {rd }}$ grade decreased a little, but by the $4^{\text {th }}$ grade this index has developed. It is difficult to make conclusion about development regularities at primary school age with such dynamics of the changes of short-term visual memory capacity because of possible faults and purity of empirical research in the framework of this paper.

However we can speak about some tendency of memory intensity and development from the $1^{\text {st }}$ to the $4^{\text {th }}$ grade, as in the $4^{\text {th }}$ grade there are no low rates of short-term visual memory.

Indexes of mediated memory intensity degree research of are presented in Table 6.

Judging from Table 6 results we can make the conclusion that mediated memory of the $1^{\text {st }}$ grade children is developed enough for this age. $2^{\text {nd }}$ grade children have also shown good results. But as for the $3^{\text {rd }}$ and the $4^{\text {th }}$ grade it is not the same, as the testees should have completed this assignment even more successfully than two 
previous grades.

However after high enough increase in the rates of mediated memory there is a decrease of average rates and there are low rates of mediated memory.

Table 5. Indexes of short-term visual memory capacity at primary school age.

\begin{tabular}{ccccccc}
\hline & \multicolumn{7}{c}{ Short-term visual memory capacity } \\
\cline { 2 - 7 } Grades & \multicolumn{7}{c}{ High results } & Average results & Low results \\
\cline { 2 - 7 } & \multicolumn{7}{c}{ Number of learners } & $\%$ & Number of learners & $\%$ & Number of learners & $\%$ \\
\hline $1^{\text {st }} \mathrm{N}=23$ & 5 & 22 & 1 & 4 & 17 & 74 \\
$2^{\text {nd }} \mathrm{N}=20$ & 4 & 20 & 16 & 80 & 0 & 0 \\
$3^{\text {rd }} \mathrm{N}=20$ & 2 & 10 & 15 & 75 & 3 & 15 \\
$4^{\text {th }} \mathrm{N}=16$ & 3 & 19 & 13 & 81 & 0 & 0 \\
\hline
\end{tabular}

Table 6. Mediated memory diagnostics results.

\begin{tabular}{ccccccc}
\hline & \multicolumn{7}{c}{ Mediated memory } \\
\cline { 2 - 7 } Grades & \multicolumn{7}{c}{ High results } & Average results & Low results \\
\cline { 2 - 7 } & \multicolumn{7}{c}{ Number of learners } & $\%$ & Number of learners & $\%$ & Number of learners & $\%$ \\
\hline $1^{\text {st }} \mathrm{N}=23$ & 14 & 61 & 7 & 30 & 2 & 9 \\
$2^{\text {nd }} \mathrm{N}=20$ & 3 & 15 & 17 & 85 & 0 & 0 \\
$3^{\text {rd }} \mathrm{N}=20$ & 7 & 35 & 9 & 45 & 4 & 20 \\
$4^{\text {th }} \mathrm{N}=16$ & 4 & 25 & 9 & 56 & 3 & 19 \\
\hline
\end{tabular}

Table 7. Memorizing dynamics rates.

\begin{tabular}{ccccccc}
\hline & \multicolumn{7}{c}{ Memorizing dynamics } \\
\cline { 2 - 7 } Grades & \multicolumn{7}{c}{ High results } & Average results & Low results \\
\cline { 2 - 7 } & \multicolumn{7}{c}{ Number of learners } & $\%$ & Number of learners & $\%$ & Number of learners & $\%$ \\
\hline $1^{\text {st }} \mathrm{N}=23$ & 5 & 22 & 16 & 69 & 2 & 9 \\
$2^{\text {nd }} \mathrm{N}=20$ & 4 & 20 & 16 & 80 & 0 & 0 \\
$3^{\text {rd }} \mathrm{N}=20$ & 2 & 10 & 18 & 90 & 0 & 0 \\
$4^{\text {th }} \mathrm{N}=16$ & 2 & 12 & 14 & 88 & 0 & 0 \\
\hline
\end{tabular}

Table 8. Memorizing productivity indexes.

\begin{tabular}{|c|c|c|c|c|c|c|}
\hline \multirow{3}{*}{ Grades } & \multicolumn{6}{|c|}{ Memorizing productivity } \\
\hline & \multicolumn{3}{|c|}{ High results } & \multicolumn{2}{|r|}{ Average results } & \multirow{2}{*}{$\begin{array}{c}\text { Low results } \\
\text { \% }\end{array}$} \\
\hline & Number of learners & $\%$ & Number of learners & $\%$ & Number of learners & \\
\hline $1^{\text {st }} \mathrm{N}=23$ & 5 & 22 & 13 & 56 & 5 & 22 \\
\hline $2^{\text {nd }} \mathrm{N}=20$ & 14 & 70 & 6 & 30 & 0 & 0 \\
\hline $3^{\text {rd }} N=20$ & 2 & 10 & 14 & 70 & 4 & 20 \\
\hline $4^{\text {th }} \mathrm{N}=16$ & 3 & 19 & 11 & 68 & 2 & 13 \\
\hline
\end{tabular}


Possible reasons of such changes in the rates of such psychic function can be, in our opinion, firstly insufficient purity of empirical research, secondly, possible tiredness of children, as diagnostics took place in the afternoon after classes and also the factor of the environment that was not taken into account, However it was the character of the assignments itself used in the educational process that determined what was developed in children and what psychic function and what its peculiarity was subject to greater development.

Table 7 presents memorizing dynamics rates.

The following conclusion can be made from Table 7: there is an increase of "memorizing dynamics" index in this case as judging from average results (as in this case most of the children are in the medium range) from grade to grade the per cent of children who coped with this assignment increases.

Memorizing productivity was researched together with dynamism index which is reflected in Table 8 .

The number of children who coped with this task is random enough. Thus, most of the children in the $1^{\text {st }}, 3^{\text {rd }}$ and $4^{\text {th }}$ grades did not cope with it and it makes approximately a quarter of the total number of children. But if to consider test results in general in all grades, the number of children who coped with this assignment is nearly a half and even more of the general number of children.

This is a definite situation, as it is primary school age when children not only learn to memorize a body of information, but also use it productively for education activity and apply it in various assignments.

The next psychic cognitive function under research was imagination the results of which are presented in Table 9.

According to the results of primary school children imagination diagnostics it is notable that such psychic process is developed successfully enough. As it is presented in Table 9 most of the $1^{\text {st }}$ grade children have average results. Less children have average result in the $2^{\text {nd }}$ and $3^{\text {rd }}$ grades but more children have high points. Nearly half of the $4^{\text {th }}$ grade children have high per cent on this method and $50 \%$ exactly have average rate.

The following conclusion can be made on the basis of the research of primary school children imagination development level: children's imagination is dynamically developing from grade to grade and the per cent of high results also increases with every grade.

Next stage studied thinking development peculiarities.

During children examination the following results were received on the presented method. ${ }^{\text {st }}$ grade children have quite good results on verbal-logic thinking development. Besides, more satisfactory results were received in the $2^{\text {nd }}$ grade. Results are a little lower in the $3^{\text {rd }}$ and $4^{\text {th }}$ grades. On the basis of this the conclusion can be made that this psychic function has various dynamics of development at different age.

Results on children diagnosis on "Raven matrix" are presented below. The rates are generalized and presented in Tables 10 and 11 in section of age, grade and selection representation.

During the study of visual-image thinking change dynamics of primary school children the following results were received that are presented in the table. As a result the conclusion can be made about the dynamics of visual-image thinking development. In this case $1^{\text {st }}$ grade children had very good results. This cannot be said about the $2^{\text {nd }}$ grade, practically half of the children did not cope with the assignment. $3^{\text {rd }}$ grade children did a little better, only $20 \%$ of the testees did not cope with the assignment. As for the $4^{\text {th }}$ grade all children under examination coped with the method. Besides if to compare research results of visual-image thinking of all the grades, it can be seen from the table that such psychic function development in every grade is at different level of the development and it does not influence children thinking abilities favorably.

Table 9. Imagination indexes at primary school age.

\begin{tabular}{ccccccc}
\hline & \multicolumn{7}{c}{ Imagination } \\
\cline { 2 - 7 } Grades & \multicolumn{7}{c}{ High results } & Average results & Low results \\
\cline { 2 - 7 } & \multicolumn{7}{c}{ Number of learners } & $\%$ & Number of learners & $\%$ & Number of learners & $\%$ \\
\hline $1^{\text {st }} \mathrm{N}=23$ & 1 & 4 & 17 & 74 & 5 & 22 \\
$2^{\text {nd }} \mathrm{N}=20$ & 5 & 25 & 7 & 35 & 8 & 40 \\
$3^{\text {rd }} \mathrm{N}=20$ & 5 & 25 & 13 & 65 & 2 & 10 \\
$4^{\text {th }} \mathrm{N}=16$ & 7 & 44 & 8 & 50 & 1 & 6 \\
\hline
\end{tabular}


Table 10. Indexes of verbal-logic thinking development at primary school age.

\begin{tabular}{|c|c|c|c|c|c|c|}
\hline \multirow{3}{*}{ Grades } & \multicolumn{6}{|c|}{ Verbal-logic thinking } \\
\hline & \multicolumn{3}{|c|}{ High results } & \multicolumn{2}{|r|}{ Average results } & \multirow{2}{*}{$\begin{array}{c}\text { Low results } \\
\%\end{array}$} \\
\hline & Number of learners & $\%$ & Number of learners & $\%$ & Number of learners & \\
\hline $1^{\text {st }} \mathrm{N}=23$ & 3 & 13 & 15 & 65 & 5 & 22 \\
\hline $2^{\text {nd }} \mathrm{N}=20$ & 9 & 45 & 8 & 40 & 3 & 15 \\
\hline $3^{\text {rd }} N=20$ & 6 & 30 & 9 & 45 & 5 & 25 \\
\hline $4^{\text {th }} \mathrm{N}=16$ & 4 & 25 & 11 & 75 & 0 & 0 \\
\hline
\end{tabular}

Table 11. Indexes of visual-image thinking development at primary school age.

\begin{tabular}{|c|c|c|c|c|c|c|}
\hline \multirow{3}{*}{ Grades } & \multicolumn{6}{|c|}{ Visual-image thinking } \\
\hline & \multicolumn{3}{|c|}{ High results } & \multicolumn{2}{|r|}{ Average results } & \multirow{2}{*}{$\begin{array}{c}\text { Low results } \\
\%\end{array}$} \\
\hline & Number of learners & $\%$ & Number of learners & $\%$ & Number of learners & \\
\hline $1^{\text {st }} \mathrm{N}=23$ & 6 & 26 & 15 & 65 & 2 & 9 \\
\hline $2^{\text {nd }} \mathrm{N}=20$ & 3 & 15 & 7 & 35 & 10 & 50 \\
\hline $3^{\text {rd }} N=20$ & 5 & 25 & 11 & 55 & 4 & 20 \\
\hline $4^{\text {th }} \mathrm{N}=16$ & 6 & 38 & 10 & 62 & 0 & 0 \\
\hline
\end{tabular}

Further the table presents the results of children diagnosis on Rubik's Cube method that allowed to trace the dynamics of the change of maturity degree of visual-efficient thinking on the basis of the data to predict its development regularity.

As it can be seen from Table 11 data not all $1^{\text {st }}$ grade children managed to cope with the assignment of the method and got enough number of points. As for the $2^{\text {nd }}$ grade $40 \%$ of the testees could not cope with the assignment. And in the $3^{\text {rd }}$ and $4^{\text {th }}$ grades there is much less number of children $10 \%$ and $25 \%$ correspondingly who have low results.

\section{Conclusion}

The conclusion can be made from the presented results that those children with low results have weakly developed image-efficient thinking. Children with average results have demonstrated visual-efficient thinking as average developed. And children with high results have demonstrated high developed visual-efficient thinking.

It is obvious that all the enumerated psychic functions are important for primary school children. They are perception, memory and imagination, but of course the most important at this age is thinking development. As it was mentioned above none of the psychic functions can be developed without thinking. Thus thinking cannot be developed without perception, memory and imagination.

\section{References}

Vygotskiy, L. S. (1982). Thinking and Speech (Collected Edition in 6 Volumes, Volume 2, p. 226). Moscow: Pedagogy. 